\title{
Genetic parameters for animal price and live-weight from routinely collected data at livestock marts
}

N McHugh ${ }^{1,2}$, R D Evans ${ }^{3}$, P R Amer ${ }^{4}$, D P Berry ${ }^{1}$

${ }^{1}$ Teagasc, Moorepark Dairy Production Centre, Fermoy, Co. Cork, Ireland, ${ }^{2}$ School of Agriculture, Food Science and Veterinary Medicine, University College Dublin, Belfield, Dublin 4, Ireland, ${ }^{3}$ Irish Cattle Breeding Federation, Highfield House, Bandon, Co. Cork, Ireland, ${ }^{4}$ Abacus Biotech Limited, Dunedin, New Zealand Email: noirin.mchugh@teagasc.ie

Introduction Most international dairy breeding programmes have selected for increased milk production. However, beef output, such as calves and cull cows, remain an important financial contribution to a dairy farm. Van der Werf et al. (1998) reported that 10 to $20 \%$ of the gross income of a dairy farm is from the sale of calves and cull cows. Possible breeding goal traits to reflect beef revenue from dairy enterprises include calf price and cull cow value. However, there is a paucity of studies that have attempted to quantify the genetic variation present in calf and cull cow value in dairy herds, due mainly to a lack of available phenotypes. The objective of this study was to estimate phenotypic and genetic parameters for calf price, cow live-weight and cow price.

Materials and methods A total of 2,967,791 live-weight and/or animal value records from 2,506,110 animals sold at 71 livestock marts in Ireland between the years 2000 to 2008 inclusive, were available. Calves were defined as animals from dairy cows sold between 2 days of age and 12 weeks of age. They were categorised into 3 age groups: 2 to 24 days, 25 to 42 days and 43 to 84 days of age. Cows were defined as animals that had calved at least once or were greater than 30 months of age at sale and were categorised into two age groups of 2 to 6 years of age, and 6 to 14 years of age. Animals were removed if their sire, maternal grandsire, herd of origin, or mart of sale were unknown. For each calf only the first record in time was retained; for cows the last record in time was retained. Calves are generally not weighed at livestock marts and therefore only individual calf price information was available for inclusion in this analysis. Calves sold between $€ 2$ and $€ 450$ were retained. For inclusion in the analyses, cows were required to weigh between 300 and $1000 \mathrm{~kg}$ and have been sold for between $€ 75$ and $€ 1500$. Cows were classified both on their fate post-sale and, as a separate variable, on days since last calving. Two contemporary groups definitions were formed for both calves and cows: mart-by-date of sale and herd-by-year of sale. Only records from contemporary groups with at least 4 other records were retained. Following all edits 40,157 calves and 17,504 cows remained. Phenotypic and genetic (co)variance components for animal price and liveweight were estimated using animal linear mixed models in ASReml (Gilmour et al., 2009. Fixed effects considered for inclusion in the models were: the two aforementioned definitions of contemporary groups, gender (for calves only), age of animal at sale (continuous variable), the proportion of the 12 most commonly found dairy and beef breeds in Ireland, calving ease (no assistance/unobserved; slight assistance; severe assistance; veterinary assistance), whether the animal was born as a singleton or twin, parity of dam (1, 2, 3, 4, 5+, missing), dam age (in months) relative to the median age within parity, heterosis, and recombination loss. When the dependent variable was cow price, the animal's lactation number was included in the model instead of dam parity and age of the animal relative to median calving age, replaced age of the dam. Fate post-sale (based on days until next calving or days to slaughter) and stage of lactation (5 classes) were also added as fixed effects. Prior to the estimation of variance components for price, residuals from a fixed effects model with price as the dependent variable and the aforementioned fixed effects, with the exception of contemporary group, were standardised to the mean residual standard deviation within the contemporary group of mart-date across the years 2004 to 2008 . It is the variance components of the standardised price that are reported in the present study. Data on live-weight was not standardised. A series of bivariate analyses were also undertaken to estimate genetic correlations between traits within and across maturity categories as well as between male and female calf price.

Results Calves sold for an average price of $€ 156$, at on average 28 days of age. Heritability for calf price varied from $0.24 \pm 0.09$ to $0.52 \pm 0.24$ across the three age groups. The genetic correlation between male and female calf price was $0.60 \pm 0.04$. Heritability estimates for cow price were moderately low for the two age groups ranging from $0.12 \pm 0.09$ (6 to 14 years of age) to $0.36 \pm 0.05$ ( 2 to 6 years of age). The genetic correlation for price between the age groups for cows was 0.70 (S.E. $=0.18$ ). Heritability estimates for cow live-weight was $0.25 \pm 0.05$ and did not vary by age group. The correlation between calf price and cow price was weak (Table 1).

Table 1 Number of records $(\mathrm{N})$, mean price in Euro and live-weight in kgs $(\mu)$, genetic standard deviation $\left(\sigma_{\mathrm{g}}\right)$, heritability $\left(\mathrm{h}^{2}\right.$; standard error in parenthesis), and coefficient of genetic variation $\left(\mathrm{CV}_{\mathrm{g}}\right)$ for calves and cows. Phenotypic (above diagonal) and genetic correlations (below diagonal; standard error in parenthesis) between price and live-weight are also presented.

\begin{tabular}{lllllllll}
\hline \hline Trait & $\mathrm{N}$ & $\mu$ & $\sigma_{\mathrm{g}}$ & $\mathrm{h}^{2}($ s.e. $)$ & $\mathrm{CV}_{\mathrm{g}}$ & Calf price & Cow price & Cow weight \\
\hline Calf price & 40,157 & 156 & 24.9 & $0.32(0.03)$ & 16.0 & & 0.04 & 0.18 \\
Cow price & 17,504 & 549 & 25.2 & $0.07(0.03)$ & 4.6 & $0.22(0.06)$ & & 0.32 \\
Cow weight & 17,504 & 600 & 27.6 & $0.25(0.05)$ & 4.6 & $0.11(0.05)$ & $0.69(0.08)$ & \\
\hline \hline
\end{tabular}

Conclusion Moderate heritability coupled with large genetic variation and the availability of routinely collected data clearly indicates that both price traits could be included in genetic evaluations of dairy cattle in Ireland as both selection criteria and as goal traits.

\section{References}

Gilmour, A.R., Gogel, B.J., Cullis, B.R. and Thompson, R. 2009. ASReml User Guide, Release 3.0.

Van der Werf, J.H.J., van der Waaij, L.H., Groen, A.F., and de Jong, G. 1998. Livestock Production Science 54, 11-20. 